\title{
Lâmpadas, corpos e cidades: reflexões acadêmico-ativistas sobre arte, dissidência e a ocupação do espaço público
}

Lamps, bodies and cities: academic-activist reflections on art, dissendence and the occupation of public space

Vitor Grunvald*

*Universidade Federal do Rio Grande do Sul - Porto Alegre, RS, Brasil vgrunvald@gmail.com

https://orcid.org/0000-0001-8299-6830 


\title{
Resumo
}

O artigo toma como centro de gravidade etnográfico práticas desenvolvidas pelo coletivo de artivismo A Revolta da Lâmpada para discutir questões relacionadas à arte, dissidência e ocupação do espaço público. Nesse contexto, trata-se de apresentar algumas ações e noções desenvolvidas por esse coletivo, bem como pensar de que maneira elas podem ser entendidas quando vistas a partir de recentes discussões sobre ativismo cultural e artístico. Por outro lado, busca-se, igualmente, questionar a noção de um espaço público como entidade dada a priori assim como problematizar de que maneira essas questões se relacionam com noções clássicas sobre democracia e cidadania.

Palavras-chave: arte; ativismo; espaço público; dissidência.

\begin{abstract}
The article takes as ethnographic center of gravity practices developed by the artivist collective A Revolta da Lâmpada in order to discuss issues related to art, dissidence and occupation of public space. In this context, it aims to explore some actions and notions developed by this collective, as well as thinking on how they can be understood in the light of recent discussions on cultural and artistic activism. On the other hand, it also seeks to question the notion of public space as an a priori given entity as well as to problematize how these issues are related to classic notions of democracy and citizenship.
\end{abstract}

Keywords: art; activism; public space; dissidence. 
Ainda vão me matar numa rua. quando descobrirem, principalmente que faço parte dessa gente que pensa que a rua é a parte principal da cidade. Paulo Leminski em Toda poesia

Ao falar sobre a "estreita vinculação entre as chamadas militantes e as pesquisadoras" na história do feminismo brasileiro, Mariza Correa (2001, p. 25), em nota, explicita que

o ponto é importante porque na visão maniqueísta que separa militantes e pesquisadoras naquele momento, perde-se de vista que nós, pesquisadoras, éramos também militantes e que, se nos desiludimos com algumas das crenças inscritas em nossas palavras de ordem, não foi porque nosso "compromisso maior era com o fazer ciência social" (Heilborn, Sorj, 1999), mas sim porque nosso compromisso maior era com a tentativa de compreender a sociedade brasileira, para mudá-la. [...] Neste sentido, não posso concordar com a afirmativa de Heilborn e Sorj de que "a área de estudos de gênero... prescinde das motivações políticas que marcaram sua origem e a primeira geração de pesquisadoras." Nenhum campo intelectual pode prescindir de sua própria história.

Na esteira do processo aludido por Correa, o artigo aqui apresentado é fruto de uma experiência de campo que é tanto ativista quanto acadêmica. ${ }^{1}$ Se, por um lado, busco construir reflexões academicamente orientadas e

1 Est e texto foi apresentado na mesa "Cidade: imagens políticas", coordenada por Claudia Fonseca no IV Ciclo Antropologia e Etnografia em Contextos Urbanos que ocorreu na UFRGS nos dias 3 e 4 de outubro de 2017. Versões iniciais dessas reflexões foram testadas na seção "Conectividade, cidade e estéticas - o Brasil a partir de suas margens" do XXXV International Congress of the Latin American Studies Association (Peru, Lima, 2017) e no grupo de trabalho "Antropologia da cidadania", coordenado por Luís Roberto Cardoso de Oliveira e Marcus André de Souza Cardoso da Silva na $31^{\mathrm{a}}$ Reunião Brasileira de Antropologia que ocorreu na UnB entre os dias 9 e 12 de dezembro de 2018. Agradeço os comentários realizados nessas ocasiões e a Regina Facchini pela leitura e comentário crítico da versão final deste artigo. Opto por, experimentalmente, manter o registro da oralidade e da informalidade em alguns trechos do texto, pois acredito que essa marca é mais adequada para a exposição dos argumentos aqui apresentados. Este e outros artigos foram escritos a partir de pesquisas apoiadas pela Fapesp. 
antropologicamente pensadas a partir de um grupo concreto, situado histórica e culturalmente, por outro, sou, hoje em dia, corpo ativante e não apenas mente pensante em relação a esse coletivo.

Sou também, o que o texto permite obliterar, um homem, branco, viado, cisgênero, ${ }^{2}$ de classe média e nascido em Belém do Pará. Vivo, há quase dez anos, na zona central de São Paulo e escrevo no final da década de 2010 em um país que, a despeito de seu lugar geopolítico, tende a se pensar como ocidental. E país no qual, há alguns anos, se intensifica o que Lia Zanotta Machado (2017) chamou de "retrocesso neoconservador".3

Antropólogo que, há 15 anos, trabalha com pesquisas relacionadas a gênero e sexualidade e que, há alguns tantos outros anos, se preocupa em pensar questões relativas à arte e política, produzo minha escrita na esperança de que o conjunto de afetos produzidos por esses campos possa se coadunar com aquele de minha própria atuação ativista n' A Revolta da Lâmpada desde o ano de 2016.

E que minha escrita, marcadamente mais ensaística que acadêmica, como me foi dito, possa abrir caminhos e suscitar reflexões mais do que propor

2 Alguns conceitos e palavras utilizadas no âmbito de minha escrita merecem algum desenvolvimento. Cistema é um termo que, como tão bem elabora Viviane Vergueiro (2015, p. 15), é uma corruptela que "entre outras corruptelas do tipo, tem o objetivo de enfatizar o caráter estrutural e institucional - 'cistêmico' - de perspectivas cis+sexistas, para além do paradigma individualizante do conceito de 'transfobia"'. A heteronormatividade, por sua vez, como pontua Leandro Colling (2015, p. 24), é termo que, "criado em 1991 por Michael Warner, busca dar conta de uma nova ordem social. Isto é, se antes essa ordem exigia que todos fossem heterossexuais, hoje a ordem sexual exige que todos, heterossexuais ou não, organizem suas vidas conforme o modelo 'supostamente coerente' da heterossexualidade. Enquanto na heterossexualidade compulsória todas as pessoas devem ser heterossexuais para serem consideradas normais, na heteronormatividade, todas devem organizar suas vidas conforme o modelo heterossexual, tenham elas práticas sexuais heterossexuais ou não. Com isso, entendemos que a heterossexualidade não é apenas uma orientação sexual, mas um modelo político que organiza nossas vidas." Em outros momentos, utilizo, inadvertidamente, cisheteronormatividade para enfatizar, seguindo a sugestão de Vivi, o caráter cistêmico da própria heteronormatividade. Por fim, para a categoria cisgênero que já adentrou o imaginário político e se insinua cada vez mais fortemente no imaginário social mais amplo, cf. o artigo de Amara Moira (Rodovalho, 2017).

3 Um dos pontos nevrálgicos das investidas neoconservadoras tem sido o que ficou conhecido como "ideologia de gênero". Para reflexões antropológicas sobre essas questões, no caso do Brasil, cf. o dossiê Conservadorismo, direitos, moralidades e violência, organizado por Regina Facchini e Horacio Sívori (2017). Cf., adicionalmente, a análise de Rogério Junqueira (2017) sobre a gênese da categoria "ideologia de gênero" e sua relação com a ideia de "família natural". E, para um panorama europeu, cf. o livro Anti-gender campaigns in Europe: mobilizing against equality, organizado por Roman Kuhar e David Paternotte (2017). 
soluções tidas como acabadas. Pois, como tão sabiamente ensinou o grande filósofo João Guimarães Rosa em Grande sertão: veredas, “[q]uerer o bem com demais força, de incerto jeito, pode já estar sendo se querendo o mal, por principiar. Esses homens! Todos puxavam o mundo para si, para o concertar consertado. Mas cada um só vê e entende as coisas dum seu modo".

De qualquer forma, miticamente, foi assim. No dia 14 de novembro de 2010, Luís Alberto Betônio caminhava pela Av. Paulista quando sofreu ataque por um grupo de jovens, um dos quais, aproximando-se dele, o agrediu com duas lâmpadas fluorescentes. O caso ganhou imensa repercussão midiática e deslanchou uma série de discussões sobre violência contra a população LGBTQIA+ no Brasil e sobre a constante impunidade diante dela.

$\mathrm{O}$ ataque foi tido como homofóbico, pois, independentemente da orientação afetivo-sexual de Luís Alberto Betônio, ele foi agredido porque leram seu corpo como um corpo inadequado para ocupar o espaço público sem sofrer algum tipo de sanção. Essa sanção, às vezes, é apenas verbal. Grita-se "viado" aqui, "traveco" ali, "sapatona" acolá. Mas não são poucas as vezes que essas ações deixam as palavras e passam para uma violência que age sobre o corpo, tentando fazer nele uma marca tão forte quanto o próprio estigma que carrega.

A questão não é nova. O espaço público nunca foi para todas. ${ }^{5} \mathrm{E}$ muitas pessoas que sofrem opressões por terem uma raça e classe específicas ou por possuírem marcas de dissidências de gênero e sexualidade já o sabem há muito tempo.

Em seu livro Notes toward a performative theory of assembly, Judith Butler (2015) nos adverte a tratar com cautela as noções de "o povo", "a democracia" e "o espaço público". A invocação dessas noções não descreve uma dada realidade, mas, sendo performativa, cria a realidade que supõe apenas descrever e, portanto, mobiliza práticas de nomeação e relações de poder específicas. O resumo da ópera é que nunca devemos dar essas noções por certas, pois nunca estão resolvidas.

4 Assim, esse texto é marcadamente político, como, ademais, qualquer outro o é. Mas, como discuti em outros momentos (Grunvald, 2009a, 2009b), enseja uma prática política pensada mais como máquina de problematização do que como centro de determinação e resolução dos problemas ditos sociais.

5 Consciente dos imbróglios políticos da escrita, utilizo o feminino universal como deslocamento de uma expectativa de linguagem que, como tão bem discutiu Haraway (1995), se pretende, ao mesmo tempo, masculina e desencarnada. 
Os enunciados que se instauram "em defesa da sociedade", para lembrar o conjunto de palestras homônimas de Foucault (2005) no Collège de France, partem do princípio que é preciso defendê-la de alguém que não é ela ou que não deveria ser. Quem está dentro e quem está fora dessa sociedade que é defendida? Contra quem brandem os tambores? A engenharia político-social do que Foucault associa à biopolítica é simultânea e mesmo dependente de sua face oculta, a necropolítica da qual fala Achille Mbembe (2016).

Mesmo espaços semipúblicos. Travestis e pessoas trans que não podem acessar banheiros. ${ }^{6}$ Pessoas pretas da periferia que são impedidas de acessar shoppings. ${ }^{7}$ Até exposições de arte que são expressões domesticadas de subversão eficiente em centros culturais de banco - domesticadas porque operam de forma que o próprio cistema heteronormativo consegue incorporá-las sem problemas, e eficientes porque ao serem incorporadas produzem lucro - mesmo elas, atualmente, são pintadas como possíveis revoluções que merecem ser combatidas em nome da moral, dos costumes, da família, da religião e mesmo de uma infância supostamente profanada. ${ }^{8}$

Seriam esses discursos, característicos do que Gayle Rubin (1992), Jeffrey Weeks (1977) e Carole Vance (1984) caracterizaram como pânico moral e sexual, a atualização da "fala do crime", expressão que Teresa Caldeira (2000) utilizou para analisar um determinado padrão de segregação socioespacial nas últimas décadas do século XX? Quais corpos podem ou não ocupar o espaço citadino sem serem lampadados ou, alternativamente, criminalizados? Que dinâmicas de segregação operam esses recortes?

A herança democrática grega vem de recônditos muito distantes de nossa realidade. Mas processos de dominação epistêmica marcados pela colonialidade do saber fazem com que muitas de nós ainda insistam em dizer que ela

6 São inúmeros os casos nos quais às pessoas trans e travestis é vedada a utilização de banheiros que são apropriados ao seu gênero e não ao gênero ao qual foram designadas ao nascer. A questão, recentemente, ganhou ares institucionais em São Paulo quando, em discussão na plenária com a deputada Erica Malunguinho (PSOL), o parlamentar Douglas Garcia (PSL) afirmou que "tiraria a tapas uma pessoa travesti ou transexual que estivesse utilizando um banheiro correspondente à sua identidade de gênero" (Condepe..., 2019). Para uma discussão acadêmica da questão, cf. Andrade (2012, p. 147-170).

7 Aqui, os casos emblemáticos são os chamados rolezinhos. Cf., por exemplo, Caldeira (2014).

8 Refiro-me, aqui, às contendas sociopolíticas em torno da exposição Queermuseu. 
tem a ver com a gente. ${ }^{9}$ Essa ideia de espaço público como espaço democrático da política e do encontro entre pares - aqueles pares que a noção de cidadãos com direitos iguais perante a lei supõe - já se coloca, portanto, como resultado da instauração de uma determinada práxis e de uma linguagem a ela associada a partir de um processo que Chantal Mouffe e Ernesto Laclau (1986) chamam de "exclusão constitutiva".

Tudo aquilo que não é entendido como apropriado a esse espaço em um determinado momento histórico e em um determinado contexto sociocultural, isto é, tudo aquilo que foge ao estabelecido padrão normativo da branquitude, da cisheteronormatividade ${ }^{10}$ e também da participação no espaço citadino como inserção num determinado mercado de consumo, tudo isso é repelido para fora do espaço entendido como público. ${ }^{11} \mathrm{~A}$ lâmpada foi apenas mais uma materialização dessa violência que é, em muitos sentidos, distribuída diferencialmente entre quem conta e quem não conta como "sociedade" e como "povo".

Para um grupo de ativistas, a lâmpada apareceu, explicitamente, como um símbolo de opressão e, no final de 2014, resolveram se manifestar publicamente no local da Av. Paulista onde Luís Alberto Betônio havia sido agredido quatro anos antes. A partir daí surge o coletivo A Revolta da Lâmpada - também referida, usualmente, apenas como Revolta ou pelo acrônimo RDL - que, de forma contínua, vem desenvolvendo uma série de ações desde então.

A lâmpada, de alguma forma, se apresenta como símbolo que coaduna diversas violências e costura opressões que podem ser ditas como macroestruturais com situações mais concretas vividas na ocupação do espaço público. Em áudio publicado no grupo de WhatsApp do coletivo, no dia 2 de maio de 2019,

9 Sobre a noção de colonialidade do saber, cf. Edgardo Lander (2000) e Aníbal Quijano (2010). Para a maneira como a noção de colonialidade tem redesenhado algumas discussões sobre teorias e éticas queer/cuir no Brasil, cf. Pereira (2012, 2015), Pelúcio (2012, 2016), Vergueiro (2015), Mombaça (2016) e Grunvald (2017).

10 Tal como sugerido pelo revisor deste artigo, a rigor, em palavras como cisheteronormatividade, cisheteronormativo/a ou cisheterocentrado/a deveria haver um hífen antes do "h", ou então a supressão dele (como em "transumano", por exemplo). Contudo, utilizo a grafia sem hifenização e com "h" para demarcar, com clareza, a unidade de um complexo político que é, ao mesmo tempo, cisgênero e heterossexual e que funciona a partir de um imperativo lógico e social que toma essas experiências de gênero e sexualidade como medida do mundo.

11 Para reflexões sobre a noção de branquitude, cf. Müller e Cardoso (2017). Para uma discussão antropológica sobre consumo, identidades e ocupação dos espaços cf. França (2012). 
em virtude de uma discussão sobre a participação numa mesa sobre agressões em evento organizado pelo Instituto Pólis, Viração e a Parada do Orgulho LGBT de São Paulo (APOGLBT), ${ }^{12}$ um dos integrantes argumenta que:

Ainda mais no contexto que a gente tá vivendo agora, a lâmpada vira muitas outras armas ainda muito mais letais, né? Literalmente ou metaforicamente [...] Desde um Museu Nacional pegar fogo até uma agressão na rua, tudo isso é uma lampadada. Seja uma lampadada de agressão ao corpo, de agressão à ideia, de agressão à cultura, né? Tem várias mortes. A morte do corpo, a morte do conhecimento. Epistemicídio. Já que a gente tá falando de direito à cidade, espaço público, a gente pode falar de quais são todas essas lâmpadas, desde armamento, até agressão de rua, até fechamento de espaços públicos ou sucateamento de espaços públicos para LGBTs e corpos dissidentes.

Desde sua primeira grande mobilização, o coletivo (ou a coletiva, no feminino, como as vezes é dito por integrantes do grupo) realiza o que chama, internamente, de "Revolta na Rua". Geralmente em novembro, um trio elétrico sai do número 777 da Av. Paulista, local onde ocorreram as lampadadas, e percorre ruas da cidade numa "manifestação pelo corpo livre". Ao longo do trajeto, diversos corpos ou corpas, também no feminino, são convidadas a falar no microfone sobre suas experiências, demandas, luta e "rexistência", ${ }^{13}$ ação que é intercalada por shows e performances de artistas cuja vivência e trajetória também lida, de alguma maneira, com essas opressões relacionadas a seus corpos.

12 O seminário se chama Direito à Cidade: de Olho na LGBTfobia e, como descrito em evento criado no Facebook, "faz parte de uma série de ações de combate à LGBTfobia, reflexão sobre os direitos da população LGBTI+ e o papel das cidades para assegurar igualdade para todes" (Direito..., 2019).

13 "Rexistência" é um neologismo que busca fundir, em um único vocábulo, as palavras "existência" e "resistência" e tem sido muito utilizado por grupos e indivíduos ligados aos ativismos contemporâneos por direitos humanos. De fato, o neologismo é muito feliz em marcar que esses processos de resistência são lutas pela existência, pois é esta última que se vê, a todo momento, ameaçada por diversos terrorismos de direita e, inclusive, por terrorismos de Estado através de seu braço armado, a polícia. No que concerne a manifestações de caráter público e coletivo, esse perigo ganha contornos ainda mais aguçados, pois, como argumenta Butler (2016, p. 12, tradução minha), "sabemos que aquelas que se reúnem nas ruas ou em domínios públicos no qual a polícia está presente estão sempre correndo risco de detenção e encarceramento [...] mesmo de morte"; e continua: “A fórmula parece suficientemente verdadeira: a vulnerabilidade é aumentada pela assembleia." 
Essas grandes manifestações de rua, suas ocupações do espaço público, com trio elétrico, shows, falas e performances, mas também com corpos e palavras dissidentes é uma espécie de ápice, ou pelo menos de catarse, de um ativismo que é feito de outras maneiras ao longo do ano.

A noção de um espaço público que deve ser ocupado se desdobra, ao longo do ano, em ações em universidades, museus, centros culturais. ${ }^{14}$ Todos espaços que, segundo a percepção do próprio grupo, são demasiado brancos, heterossexuais, cisgêneros e marcados por pertencimentos de classe relacionados ao acesso a um capital que não é apenas econômico, mas também simbólico.

Na chamada do primeiro grande ato de 2014, a página desse evento no Facebook informava que

a revolta da lâmpada nasce derivada da nova parada LGBT organizada no RJ em 12 de outubro, com o mesmo modelo: descentralizada, desinstitucionalizada, coletiva, criativa, independente e com equilíbrio de protagonismo entre corpos. ela é, ao mesmo tempo:

LUTA: uma ação política pragmática, com pauta clara de reinvindicações para: população LGBT, mulher e minorias criminalizadas.

FERVO: um espaço de livre expressão artística e de gênero, onde se luta pelo direito de um corpo livre ao mesmo tempo em que se vive e celebra ele. porque FERVO TAMBÉM É LUTA. (A Revolta..., 2014).

A dita "nova parada LGBT" do Rio surgiu como uma espécie de protesto em relação à Parada do Orgulho LGBT do Rio de Janeiro que seria realizada no período de eleições presidenciais e foi adiada para novembro. As pautas da primeira diferem da última, já que abordam temas que, via de regra, não foram contemplados por sua agenda política, como legalização do aborto e o fim de isenção fiscal para instituições religiosas, por exemplo. ${ }^{15}$

14 Para algumas das ações desenvolvidas pelo coletivo, cf. Centros... (2018), Cicla... (2015), Mini-Revolta... (2017).

15 Mais do que proposições e propostas políticas que podem ser, simplisticamente, contrapostas, divergências de abordagem e perspectiva entre essas manifestações, bem como entre grupos de ativismo, devem ser colocadas sob o crivo histórico e apontam para diferenças geracionais que devem ser levadas em conta no entendimento desses processos de luta e rexistência, algo que, no entanto, não enfatizarei neste artigo. Agradeço Regina Facchini pelo comentário em relação a essa questão. 
A noção de que "fervo também é luta" - mote que constitui o âmago do caráter artivista da Revolta - diz respeito à ênfase de que a arte e as formas expressivas podem ser mobilizadas de maneira a (re)inventar práticas políticas que sejam capazes de afetar e suscitar reflexões e adesões por parte das pessoas que não são mais atingidas por discursos formais e racionalistas tanto de uma "esquerda tradicional" quanto do dito "movimento institucional(izado)". ${ }^{16}$

Isso não quer dizer, contudo, que o coletivo não estabeleça relações de parceria e contato com essas esferas de atuação e mesmo, eventualmente, possa disputar tensões que são colocadas na esfera do Estado. Com efeito, a Revolta participava de muitas das reuniões da Associação da Parada do Orgulho LGBT de São Paulo (APOGLBT-SP) e sua atuação foi fundamental na escolha do tema da Parada de 2018, "Poder para LGBTI+ Nosso voto, Nossa voz".

Contudo, as discordâncias com alguns aspectos do tipo de atuação da APOGLBT e com a maneira como lidavam com as demandas internas de pessoas vivendo com hiv/aids ${ }^{17}$ fizeram com que o grupo, juntamente com os coletivos Loka de Efavirenz ${ }^{18}$ e AMEM, ${ }_{19}^{19}$ se retirassem, em protesto, dessas reuniões em outubro de 2017. A partir daí, ficou acordado que aquelas que seguissem participando dessas reuniões o fariam de forma independente e não como integrantes do coletivo.

De fato, não se trata de uma contraposição clara e delimitada entre artivismo de inspiração queer e ativismo institucional marcado pela interação socioestatal, mas de uma aposta política em outra forma de articulação e funcionamento. A não institucionalidade e a horizontalidade, afirmadas, inclusive,

16 Não é à toa que um dos eventos realizados pela RDL em 2017, no Museu de Arte São Paulo Assis Chateaubriand (Masp-SP), se tratava de uma oficina intitulada Artivismo da fechação: estratégias de luta para rachar menos e somar mais (cf. Artivismo..., 2017). Para essa atividade, o grupo convidou e contou com a participação do coletivo artivista Visto Permanente (cf. https://www.facebook.com/acervovistopermanente/, dedicado a questões relativas à imigração, do coletivo de homens trans Meninos Bons de Bola (cf. https://www.facebook.com/Mbboficial/) e da ativista Leandrinha Du Art (cf. https://www.facebook.com/LeandrinhaDuArt/, acesso em 18/01/2018).

17 Utilizo a grafia em minúsculo para demarcar, junto com outras pesquisadoras e ativistas do movimento de pessoas vivendo com hiv/aids (PVHIVA), certa perspectiva crítica em relação ao pânico moral e sexual que tem acompanhado as discussões sobre o tema desde o início da epidemia na década de 1980.

18 Cf. https://www.facebook.com/LokadeEfavirenz/ (acesso em 18/01/2018).

19 Cf. https://www.facebook.com/ColetivoAmem/ (acesso em 18/01/2018). 
na veemente negação do coletivo de adquirir, juridicamente, o estatuto de organização não governamental (ONG), não são discutidas e afirmadas pelo grupo como verdades transcendentes que devam ser observadas em todo e qualquer ativismo, já que muitas integrantes reconhecem a necessidade de uma atuação política que se constrói pela via institucional em diálogo com o Estado.

E se, por um lado, o tipo de artivismo levado a cabo pela Revolta da Lâmpada se afasta do tipo de atuação política empreendida por grupos mais institucionalizados e verticalizados, por outro lado, também busca estar atento às cooptações espúrias de outros tipos de manifestação que se autointitulam artivistas e engajadas, mas que, segundo a percepção do grupo, buscam se valer do caráter político do fervo para erigir verdadeiras empresas sociais. ${ }^{20}$

Esse é, talvez, o cerne do imbróglio com o Unidos do Baixo Augusta, em 2018, que convidou a Revolta para uma parceria que, ao final, parece ter se revelado como um complicado embuste entre partes pensadas como desiguais e hierarquicamente posicionadas. Ao fim e ao cabo, parece que, como foi discutido inúmeras vezes dentro do coletivo, "nossa cultura entra na buátchy, mas nossos corpos não" e, para além da politização carnavalesca como estratégia de resistência, "fervo também é lucro!" ${ }^{21}$

No texto publicado no evento do Facebook, convocando para a primeira "Revolta na Rua", exigia-se dos participantes o que chamaram de "Pacto Pão-Com-Ovo: todos que comparecerem se comprometem a não discriminar outra pessoa pela raça, classe, afetação, peso, religião ou lugar onde mora". No cerne desse pacto já estava a ideia que viria a se tornar central para A Revolta da Lâmpada: a noção de corpo livre. No texto do evento desta primeira manifestação que, mais tarde, serviria de base para o seu manifesto, o coletivo escreveu:

20 A noção de empresa social, aqui, é marcada pelo que chamo de cultura mercadológica da diversidade e consiste em um dispositivo de marketing que, vis-à-vis a necessidade de incorporação de práticas inclusivas, encampadas pela noção de responsabilidade social e/ou diversidade, se apropria de corpos, imagens, ideias e falas de sujeitos que estão, historicamente, fora dos padrões hegemônicos que regem sua prática discursiva e seu escopo de atuação. Esse processo é levado a cabo com vistas à construção de uma imagem corporativa positiva qua socialmente relevante e comprometida. E, em alguns casos, a estratégia visa mesmo escamotear o caráter mercadológico de suas iniciativas.

21 "Fervo também é lucro" foi o título do texto publicado no Facebook pela Revolta da Lâmpada no dia 7 de fevereiro de 2018 (cf. A Revolta da Lâmpada, 2018). Devido a limitações intrínsecas a um artigo como este, deixo a análise e exploração das questões envolvidas nesse caso para outro momento. 
a lâmpada fluorescente virou um símbolo da opressão não só aos LGBTs, mas a todos os corpos percebidos como inadequados pelo modelo hegemônico.

a revolta da lâmpada é uma revolta pela liberdade de todo corpo.

o corpo que é lampadado literal ou metaforicamente por ser como se é e utilizado como se deseja.

o corpo que veste a identidade de gênero que assume, e adaptável a outras.

o corpo que se mexe, ama, fala, fode, beija, toca ou se transforma de jeitos diferentes, à margem das hegemonias do mexer, do amor, da fala, da foda, do beijo, do toque ou da transformação.

o corpo que questiona a norma, que não precisa se moldar a um padrão, que não pede VIP pro opressor para entrar na boate que ele frequenta.

o corpo que aborta.

o corpo violentado por andar livre.

o corpo transformado, cuja forma original não representa a pessoa que carrega. o corpo que tinha pinto e agora tem vagina, e vice-versa.

o corpo que utiliza o aparelho excretor para outros fins deliciosamente não reprodutores.

o corpo pintoso, afeminado, aviadado, fechativo.

o corpo de macha, de dyke, de sapatão.

o corpo de peito e pau.

o corpo de barba e salto.

o corpo grande ou pequeno ou peludo ou pelado.

o corpo negro, branco, vermelho ou amarelo.

o corpo que envelhece.

o corpo que busca outros estados de consciência.

o corpo inclassificável.

o corpo permitido.

o corpo político.

o corpo que segue um padrão hegemônico por opção, mas luta pelo direito dos que não seguem.

o corpo que deseja ter direito de ser o que é, não importa o que for.

(A Revolta..., 2014).

Na concentração da manifestação, foram distribuídos balões infláveis brancos, de formato fino e alongado, que lembravam lâmpadas fluorescentes e que 
seriam, ao longo da caminhada, transformados por muitas pessoas, dando origem, por exemplo, a paus que eram colocados no meio das pernas em atos simulados de sexo público.

Antes ainda do início da caminhada, uma das atividades propostas pela Revolta foi um desfile no qual os corpos dissidentes que ali estavam passavam sobre uma passarela feita de banners da revista Veja, epítome do reacionarismo político e da falta de ética jornalística. Essa ação, intitulada pela coletiva de "catwalk ativista", foi realizada em diversos outros momentos nos anos subsequentes e parece marcar, de forma explícita, a ênfase na luta por livre circulação de corpos dissidentes em espaços públicos.

Em outro momento, organizou-se um "deitaço", em que todas se deitaram por alguns minutos no asfalto, num gesto de solidariedade à atriz Letícia Sabatella, que foi exposta pela mídia por ter deitado no chão, depois de sair de um bar em Brasília, em outubro de 2014. ${ }^{22} \mathrm{~A}$ enxurrada de críticas em relação à atitude da atriz deixou claro o controle constante a que nossos corpos estão submetidos, e contra esse policiamento o "deitaço" foi uma performance tanto estética quanto política. ${ }^{23}$

Após o sucesso dessa primeira manifestação, o grupo de ativistas envolvido na sua organização achou que valia a pena seguir realizando ações, o que gerou o coletivo que é constituído por pessoas com corpos e reivindicações diversas, pois, como atesta uma de suas bandeiras adiantadas em forma de hashtag, \#RepresentatividadeImporta. ${ }^{24}$

A coletiva não tem uma formação permanente, ainda que algumas pessoas sejam atuantes desde o seu início. É composta por pessoas brancas e pretas, trans e cis, heterossexuais, mas também viados, sapatões, pessoas que, como

22 Cf., por exemplo, Letícia... (2014).

23 Para a noção de performance estética, cf. Turner (1974). Para uma consideração da maneira como performances estéticas e sociais podem se imiscuir umas na outras no teatro vivido do cotidiano, cf. Dawsey (2005).

24 A questão da representatividade é pensada, inclusive, como algo importante para desenvolvimento de uma prática interseccional dentro do grupo. Dessa maneira, quando acionadas para fazer alguma fala, são os corpos que possuem tal vivência aqueles que farão as vias de coletivo. Para uma discussão acadêmica sobre a perspectiva da interseccionalidade, cf. Piscitelli (2008). Importante pontuar que, dentro do coletivo, há uma discussão constante sobre o que significa ter uma prática interseccional para além de uma perspectiva interseccional, algo que, contudo, não poderei tratar neste artigo. 
eu, vivem e outras que não vivem com hiv/aids, de classe média que moram na região central e também mais pobres e periféricas. ${ }^{25}$

Em março de 2015, foi realizado o "Passaço de cadáver do Eduardo Cunha", inspirado pela declaração do então líder da Câmara dos Deputados que afirmara que a discussão sobre a legalização do aborto só iria adiante por cima do seu cadáver. Na ação, diversas pessoas passaram por cima de um boneco-defunto do deputado, indicando que as reivindicações sobre o direito da mulher em relação ao seu corpo não seriam silenciadas. ${ }^{26}$ "Em defesa do corpo livre!", mote que não cansam de entoar.

Em parceria com o [SSEX BBOX], realizaram também uma performance intitulada Amazonas do Fervo, que satiriza e se opõe aos Gladiadores do Altar, grupo protofascista de jovens organizado pela Igreja Universal e treinado com "disciplina de militares". ${ }^{27}$ Além de artistas e celebridades LGBTQIA+ terem participado da performance, foi realizado um vídeo, produzido pelos dois coletivos e por Kiko Goifman, conhecido cineasta mineiro.

O [SSEX BBOX] - SEXUALIDADE FORA DA CAIXA é, tal como nos diz seu site, "um projeto de justiça social que busca oferecer perspectivas plurais sobre sexualidade e gênero a partir do relato das experiências de pensadorxs, educadorxs, ativistas, artistas e outras pessoas que vivem, aprendem e amam 'fora da caix(inh)a". ${ }^{28}$

O projeto é encabeçado por Pri Bertucci e possui (ou possuía) núcleos em São Paulo, São Francisco e Barcelona. Iniciou suas atividades em 2011 com um conjunto de webdocumentários e propôs a realização de uma grande conferência internacional que aconteceu em 2015 e, posteriormente, em 2016 e 2017, a partir de uma parceria com o Festival Mix Brasil, evento de cinema e cultura LGBTQIA+ que acontece há mais de 20 anos em São Paulo.

25 Apesar de sua diversidade interna, são constantes as discussões, tanto pelo WhatsApp quanto em reuniões presenciais, sobre como a participação de mais pessoas pretas e trans deve ser incentivada e possibilitada pelo grupo.

26 Para mais informações, cf. Passaço... (2015). Para um vídeo da ação, cf. https://www.youtube. com/watch?v=U-iUEDhf8g4 (acesso em 06/01/2018).

27 Para o vídeo de Amazonas do Fervo, cf. https://www.youtube.com/watch?v=WYmKmDgnK14 (acesso em 06/01/2018).

28 Cf. http://www.ssexbbox.com (acesso em 06/01/2018). 
Para angariar fundos para a conferência, realizou, ao longo de 2015, diversas Ocupações na Casa da Luz, com mesas de debates, shows, performances e exposição de diversos projetos artísticos que trabalham com questões relacionadas a gênero e sexualidade. ${ }^{29}$

Nessas ocasiões, diversos outros coletivos e ativistas políticos e culturais puderam entrar em contato e discutir pautas que nem sempre se restringiam a gêneros e sexualidades dissidentes e se relacionavam, por exemplo, com questões do direito à cidade e culturas periféricas. ${ }^{30}$

Neste artigo, não objetivo pormenorizar as ações desse coletivo ou mesmo discutir, de forma mais detida, aspectos específicos do cotidiano d'A Revolta da Lâmpada. Contudo, gostaria de sublinhar alguns pontos de seu ativismo, atentando, primeiramente, para a maneira como arte e política ou ética e estética se encontram aí umbilicalmente ligadas e, posteriormente, para as maneiras como esse ativismo se relaciona com uma determinada noção de espaço público e de sua subversão.

Para entendermos mais claramente as demandas e ações da Revolta, contudo, é necessário retomar o processo pelo qual o movimento então chamado de homossexual, cujas primeiras organizações haviam sido criadas majoritariamente por homens gays, passa a ser composto por outros grupos e coletivos cuja ação política é creditada paulatinamente a um conjunto cada vez mais amplo de categorias sociais.

Carvalho e Carrara (2015) descrevem esse fenômeno na história do movimento nos termos de uma espécie de federação de identidades, enfatizando a multiplicação de categorias no que passaria a ser reconhecido como um alfabeto ou uma sopa de letrinhas (Facchini, 2005). Já em relação às conexões entre movimento LGBTI e esferas governamentais, como apontam Aguião, Vianna e Gutterres (2014), é durante a década de 1990 e início da década seguinte que as questões de saúde relacionadas a mulheres, pessoas racializadas e dissidências

29 Alguns dos videorretratos que acompanham minha tese de doutorado, bem como o projeto Leather Souvenir (experimentação estético-existencial de imaginação etnográfica realizada em parceria com DOM BARBUDO, DOMINADOR de BDSM) foram exibidos em algumas destas Ocupações.

30 Para uma discussão sobre ativismos urbanos que vêm tratando de temas relativos à ampliação de direitos à cidade e que possuem muitos pontos de contato com questões tratadas neste artigo, cf. Frúgoli Jr. (2018). 
sexo-genéricas passam a se expandir em outras direções, adquirindo um caráter mais amplo e se inserindo em lutas relacionadas à garantia de direitos humanos.

Esse processo se desenvolve na articulação intensa desses movimentos por direitos em organizações não governamentais, um processo que Regina Facchini (2005) chamou de onguizacão e que é caracterizado por atividades financiadas por organizações internacionais e programas de saúde cuja marca é a prestação de serviços.

Nos anos 2000, houve uma ampliação dos espaços de interação socioestatal com o objetivo de propor e elaborar políticas públicas, disseminando um modelo de participação marcado pela lógica burocrática de funcionamento do Estado e consolidando o processo que Carvalho e Carrara (2013) chamaram de empoderamento tutelado. A partir de um conjunto de entrevistas, Aguião, Vianna e Gutterres (2014) ressaltam também que a própria militância passa a identificar essa década como o momento em que o movimento começa a construir políticas públicas e a assumir o papel de gestor.

Por outro lado, essa institucionalização do movimento acabou por suscitar, como contrapartida, um ativismo que buscava operar fora dos grilhões das esferas estatais e das atuações estruturadas de ONGs, com uma simultânea crítica à maneira como as demandas relativas aos corpos e experiências desses sujeitos haviam sido cooptadas pela lógica que, durante muito tempo, o próprio movimento tentava combater. ${ }^{31}$

Autores como Leandro Colling (2015) têm trabalhado essa tensão através de uma distinção entre ativismo institucionalizado e outro de cunho mais libertário, inspirado por teorias e éticas queer/cuir e cujas estratégias buscam menos a alocação no Estado e absorção por ele e mais um conjunto de manifestações que se valem da arte para adiantar confrontações e causar disrupturas em uma norma que é percebida como masculina, cisheterocentrada e branca.

31 Em diálogo com as pesquisas de Stephanie Lima (2016) sobre o Encontro Nacional Universitário de Diversidade Sexual (ENUDS) e de Carla de Castro Gomes (2018) sobre a Marcha das Vadias do Rio de Janeiro, Regina Facchini (2018, p. 323-329), num texto sobre os 40 anos do movimento LGBTI, argumenta que um terceiro momento de sua história, iniciado nos anos 2000 e intensificado nos 2010, é marcado por uma ênfase na experiência e no corpo, pela descrença na política institucional e a consequente valorização da horizontalidade, autonomia e espontaneidade. Esse contexto, argumenta a autora, torna propício o surgimento de artivismos como os aqui caracterizados a partir d'A Revolta da Lâmpada. 
De fato, a confluência entre experiência política e criação estética em diversas manifestações e ações coletivas contemporâneas já foi apontada e discutida por diversos pesquisadores. O historiador André Mesquita (2011) argumenta, por exemplo, que várias ações políticas desde os anos 2000 já vinham se instituindo consonantemente a experimentações estéticas alheias ao universo artístico em si e que utilizavam conceitos e imaginários do ativismo político para seu processo criativo, algo também enfatizado por Di Giovanni (2012) em seu livro Artes do impossivvel: ação de rua no movimento antiglobalização.

Essa mesma autora, em um artigo programático sobre o conceito de artivismo, afirma que, nessas formas de ação coletiva, "afastando-se de uma lógica de reivindicações e resultados, o protesto político se revelava inequivocamente como momento de desorganização e reorganização da experiência social, aproximando-se em seu caráter experimental dos processos de criação artística" (Di Giovanni, 2015, p. 16).

Se tomadas a partir de conceitos tradicionais de ação política e prática artística, essas manifestações e ações coletivas apresentam problemas para se adequarem a ambos os rótulos e perigam não ser nem uma nem outra. Como esclarece Di Giovanni (2015, p. 14, grifo da autora):

Por um lado trata-se de formas histórica e simbolicamente associadas ao ativismo, ao protesto, a irrupção de processos coletivos de auto-organização, denúncia e reivindicação de direitos, acirrados em momentos de crise econômica e social, que mesmo quando relativamente autônomos em relação às estruturas organizativas e instituições precedentes (partidos, sindicatos, movimentos setoriais), mobilizam recursos e repertórios próprios do campo de relações que nos acostumamos a chamar de política. Ao mesmo tempo, trata-se de experiências coletivas mal contidas pelas fronteiras convencionais da política em sentido estrito, formas de dissenso e reivindicação que mais se aproximam à dimensão cotidiana dos "modos de vida" e "contraculturas" do que das estruturas programáticas e ideológicas que o senso comum atribui aos movimentos sociais. Ao mesmo tempo em que habitam o universo da ação e da organização política, trata-se de modos de intervenção notavelmente ligados a práticas experimentais próprias dos mundos da arte ou, em muitos casos, explicita ou implicitamente informadas pela história do deslizamento da[s] práticas artísticas para 
fora do campo de autonomia que define a arte moderna, ao encontro de outras dimensões da vida social.

É certo, portanto, que, remetendo-se a ambos os campos antes idealmente estanques e separados, essas mudanças no fazer político não aconteceram sem uma concomitante transformação no fazer artístico.

Na introdução da clássica coletânea The traffic in culture, publicada, em 1995, por George Marcus e Fred Myers, estes autores chamavam atenção para o fato de que "na vida cultural contemporânea, a arte veio ocupar um espaço há muito associado à antropologia, transformando-se em um dos principais lugares para rastrear, representar e performar os efeitos da diferença na vida contemporânea" (Marcus; Myers, 1995, p. 1, tradução minha). Nessa mesma coletânea, foi publicado o influente artigo de Hal Foster (1995) sobre o crescente interesse de artistas pela antropologia e pela etnografia naquilo que ficou conhecido como "virada etnográfica" ou "virada social" na arte.

Roger Sansi (2015, p. 2) discute essa geração de artistas "menos interessados em arte como uma forma de auto-expressão do que em trabalhar nos espaços públicos e em locais específicos, desenvolvendo pesquisa com grupos sociais e abordando questões de relevância política imediata". Segundo o autor, essa geração está menos interessada na arte em si e mais naquilo que pode fazer com a arte, isto é, de que maneira ela pode ser instrumento de transformação social e política, o que, sem dúvida, aproxima esses artistas de artivistas cuja atuação se dá tanto em espaços de ativismo quanto em instituições do mundo artístico.

No entanto, para que nos aproximemos do tipo de artivismo levado a cabo por coletivos de inspiração queer e interseccional como A Revolta da Lâmpada, é necessário o abandono da restrita noção de arte aludida acima ou, antes, seu alargamento, já que as proposições artísticas e políticas aí engendradas não visam apenas "rastrear, representar e performar os efeitos da diferença na vida contemporânea", mas visam igualmente denunciá-los e modificá-los e, nesse sentido, só se aproximam da antropologia se esta se avizinhar da política. Não apenas escrever a cultura, como queria Geertz (1989), mas um escrever contra a cultura, como conclama Lila Abu-Lughod (1991).

O caráter de crítica cultural é marcante no cenário desses novos ativismos, pois não se trata, como apresentado na pesquisa de Holston (2008), apenas da 
construção de uma cidadania insurgente que visa denunciar o Estado e seu aparato jurídico como produtor de desigualdades, na mesma medida em que se passa a dominar e mobilizar a linguagem dos direitos para fazer frente à esse cenário. Tampouco se trataria apenas de uma mudança de ênfase de um modelo tradicional, fundamentado no princípio de incorporação ao Estado-nação, para uma cidadania que expressaria desejos e demandas por direitos à cidade.

Tanto no que concerne ao Estado quanto no que diz respeito ao acesso a espaços e equipamentos citadinos, bem como a direitos compensatórios na base de uma concepção de igualdade como tratamento diferenciado (Cardoso de Oliveira, 2015), trata-se de denunciar também um padrão cultural que é excludente e discriminatório e cuja lógica as categorias acionadas por esses movimentos buscam denunciar.

Para esses ativismos, os processos de inclusão ou exclusão, igualdade ou hierarquia e acesso ou restrição à cidadania são conformados a partir de determinações que são, antes de tudo, alocadas no corpo. O que está em jogo é o corpo e suas determinações. E se a cultura é não apenas corporificada, mas diferencialmente marcada no corpo, também deve sê-lo a política, assim como a própria ciência (Haraway, 1995). São as marcas de gênero, sexualidade, raça, classe, deficiência, geração e assim por diante que devem ser levadas em conta na construção de um conjunto amplo de ações capazes de produzir uma cidadania mais inclusiva.

Nesse cenário, toda cidadania deve ser entendida como cidadania de um corpo que não é nunca o corpo genérico do cidadão, mas um corpo de homem ou mulher, pobre ou rica, negra ou branca, heterossexual ou lésbica, trans ou cis, com ou sem deficiência, que vive com hiv/aids ou não, etc. Não há espaço para o sujeito liberal de direito, universal e incorporal. E, como adverte Leticia Sabsay $(2013,2016)$, não devemos perder de vista quais as consequências da inscrição de demandas de liberação sexual, de gênero e raciais na linguagem de direitos, algo que esse ativismo dito não institucionalizado e de inspiração queer têm constantemente insistido.

$\mathrm{Ou}$, antes, talvez tenhamos passado do momento inicial de uma ênfase absoluta na noção de direitos para outro momento no qual essa perda de inocência se desdobra em considerações sobre como alguns direitos não apenas são inacessíveis a corpos e sujeitos que não podem acessá-los, mas, de forma 
produtiva, criam exclusões que colocam outros corpos e sujeitos como corpos descartáveis que fazem girar a máquina necropolítica de Estado.

Tais casos ficam evidentes no caso do homonacionalismo discutido por Jasbir Puar (2007) a partir da estratégia do Estado de Israel que utiliza os direitos LGBTQIA+ para criar uma imagem moderna de adesão aos direitos humanos, escamoteando, com uma cortina de fumaça, a violência e o massacre que destinam ao povo palestino, no que ficou conhecido como pinkwashing.

$\mathrm{Ou}$, como discute novamente a antropóloga de origem palestina Lila Abu-Lughod (2002) no texto "As mulheres muçulmanas realmente necessitam de salvação?", quando a retórica do salvacionismo, do feminismo e dos direitos humanos é utilizada para produzir processos de hierarquização que operam a partir de conceitos raciais e temporais.

Essa autora retoma o discurso que Laura Bush, então primeira-dama dos EUA, fez à nação em cadeia nacional, pelo radio, no dia 17 de novembro de 2001. No pronunciamento, ficava explícito o enunciado, pressuposto por grande parte da mídia, de que importava menos a análise de conjunturas políticas e históricas relativas ao Afeganistão em particular e aos países árabes em geral do que conexões que podem ser pensadas como religiosas e culturais.

Esses elementos culturais eram privilegiados, justamente, por serem aqueles capazes de recriar a geografia imaginativa colonial através de uma série de contrastes: Ocidente versus Oriente, nós versus eles, cidadãos laicos que operam a partir da lógica dos direitos humanos versus crentes religiosos que operam a partir de dogmas irracionais. E também: culturas nas quais primeiras-damas fazem discursos versus outras culturas nas quais mulheres circulam silenciosas com suas burcas.

Laura Bush faz uso da retórica feminista para marcar que a ofensiva estadunidense no Afeganistão não é a ofensiva contra a soberania de um povo, tampouco um empreendimento que desconsidera e viola a hegemonia cultural dos direitos humanos. Antes, trata-se de uma empresa política e bélica que visa salvar mulheres dos grilhões de sua própria cultura e um Estado marcado pela barbárie de um primitivismo que ainda não alçou os valores democráticas tão difundidos e supostamente defendidos pelo Ocidente.

O ponto aqui é que não podemos mais fazer uma defesa cega de quaisquer direitos sem levarmos em conta a que servem, por que corpos falantes, para utilizar a expressão de Paul B. Preciado (2002), são reivindicados e enunciados 
e, assim, criados performativamente num processo que é tanto de vida quanto de morte.

Ativismos como os d'A Revolta da Lâmpada talvez ensejem uma noção de cidadania que, sem desconsiderar os direitos, não se restringem a eles. Ao realizar suas performances, vídeos, manifestações e festas, a Revolta comprime arte e política num limiar de dissolução de fronteiras definidoras de campos e práxis específicas. O que costura e articula seu artivismo é a proposição, colocada a todo momento, de que o corpo - que nada tem de abstrato, universal ou não marcado - é a ancoragem primeira de toda e qualquer cidadania; que é, essencialmente, político e deve ser livre para amar e circular no espaço público.

No entanto, para retomar os argumentos de Butler (2015), esses "espaços de aparição" da teoria arendtiana se construíram justamente a partir da exclusão de corpos e sujeitos tomados como proto ou infrassociais. Mulheres, crianças, pessoas escravizadas, essas jamais tiveram acesso ou legitimidade de fala no espaço público.

Da mesma maneira, formas de organização e agência levadas a cabo por esses corpos dissidentes foram, elas também, deslegitimadas em prol de uma práxis política própria daquilo que foi constituído como "espaço público".

A esfera pública de Habermas é apenas a imagem mais bem-acabada de um modelo coercitivo que é social e nos apresenta o espaço público como marcado pelo discurso e argumentação formais, nos quais devem ser observadas atitudes corporais específicas, regras bastante restritas e, preferencialmente, uma cultura letrada produzida pela razão iluminista que o discurso formal encarna.

Butler (2011, tradução minha) escreve que "essa visão desconsidera e desvaloriza essas [outras] formas de agência política que emergem precisamente nesses domínios considerados pré-políticos ou extrapolíticos", onde poderíamos, a propósito, colocar a própria arte.

E Renato Janine Ribeiro (1998, p. 103), ao falar sobre a palavra democrática, argumenta que, historicamente, "tornou-se lugar-comum [...] dizer que há democracia quando cessa o uso da violência, assim entendida essencialmente a forma física". O corolário dessa percepção é a associação inextricável entre argumentação verbal e prática de cidadania, mas, como nos lembra tanto Butler quanto Ribeiro, não é qualquer discurso verbal que é autorizado nesse espaço.

Ao colocar os direitos sociais na ótica dos sujeitos que os pronunciam, Vera da Silva Telles (1999, p. 180) argumenta que 
o que desestabiliza consensos estabelecidos e instaura o litígio é quando esses personagens [aqui entendidos como grupos dissidentes] comparecem na cena política como portadores de uma palavra que exige seu reconhecimento sujeito falantes, como define Rancière, que se pronunciam sobre questões que lhes dizem respeito, que exigem a partilha na deliberação de políticas que afetam suas vidas e que trazem para a cena pública o que antes estava silenciado, ou então fixado na ordem do não pertinente para a deliberação política.

Para além de "corpos em aliança" na constituição de uma "política das ruas" (Butler, 2015), as falas, textos e discursos d'A Revolta da Lâmpada utilizam uma linguagem bastante diferente da que usualmente vemos em discussões e embates tidos como apropriados ao espaço público: pajubalizam sua linguagem (fazendo alusão ao pajubá, linguagem que usa elementos do iorubá e é língua de resistência de travestis e pessoas trans) e, ao fazê-lo, também deformam o discurso público da política a partir de palavras e expressões tidas como de baixo calão, demasiado marcadas como são pelas impropriedades do corpo em detrimento da justa racionalidade da mente..$^{32}$

"Pau", "buceta", "cu" e outros termos bons o suficiente para conversas informais em bares e para sussurros nos ouvidos de amantes são recolocados na linguagem pública que os havia banido. O humor também aparece como fundamental e, para acionar elementos da convocatória de voluntárias de 2017,

é tempo de RESSUSCITAR e ocupar a rua com força total, é tempo de furacão sapatão, de terremoto preto, de tsunami travesti, de gordas sísmicas, de tornado vyado, de incêndio feminista, de um maremoto positivo de corpos vulneráveis que se fortalecem juntos, é tempo de chuca ácida, de armas queermicas, de fazer buraco na camada d’OZOMI. (A Revolta da Lâmpada, 2017).

As ações de coletivos como A Revolta da Lâmpada, ao tornarem indissociáveis práticas políticas, criações estéticas e existências corporais e ao fazerem da rua, epicentro do que tomamos como espaço público, seu próprio palco, promovem um tipo de artivismo que nos mostra que, para além ou aquém do que nos

32 Para uma análise sobre expressões de ativismo que se valem desse tipo de linguagem e, de forma cada vez mais latente, das mídias sociais para adiantar suas pautas, cf. Ferreira (2017). 
informa certa teoria política clássica, a reunião de pessoas em espaços públicos pode não ser um meio para alcançar um fim, mas um fim em si mesmo. Não se reúnem para fazer política, mas fazem política ao se reunirem e reivindicarem que esses corpos pretos, femininos, afetados e fechativos serão, eles também, parte daquilo que se constituiu à custa de sua exclusão.

\section{Referências}

ABU-LUGHOD, L. Writing against culture. In: FOX, R. (ed.). Recapturing anthropology: working in the present. Santa Fe: School of American Research Press, 1991. p. 137-154.

ABU-LUGHOD, L. Do Muslim woman really need saving? Anthropological reflections on cultural relativism and its others. American Anthropologist, v. 104, n. 3, p. 783790, 2002.

AGUIÃO, S.; VIANNA, A.; GUTTERRES, A. Limites, espaços e estratégias de participação do movimento LGBT nas políticas governamentais. In: LOPES, J. S. L.; HEREDIA, B. (org.). Movimentos sociais e esfera pública: o mundo da participação: burocracias, confrontos, aprendizados inesperados. Rio de Janeiro: CBAE, 2014. p. 237-268.

ANDRADE, L. N. de. Travestis na escola: assujeitamento e resistência à ordem normativa. 2012. Tese (Doutorado em Educação) - Faculdade de Educação, Universidade Federal do Ceará, Fortaleza, 2012.

ARTIVISMO da fechação: estratégias de luta para rachar menos e somar mais. Masp Inscrições, 2017. Disponível em: http://maspinscricoes.org.br/Oficinas/detalhes/129. Acesso em: 18 jan. 2018.

BUTLER, J. Bodies in alliance and the politics of the street. 2011. Disponivel em: http:// scalar.usc.edu/works/bodies/Judith Butler: Bodies in Alliance and the Politics of the Street | eipcp.net.pdf. Acesso em: 30 set. 2018.

BUTLER, J. Notes toward a performative theory of assembly. Cambridge: Harvard University Press, 2015.

BUTLER, J. Rethinking vulnerability and resistance. In: BUTLER, J.; GAMBETTI, Z.; SABSAY, L. (ed.). Vulnerability in resistance. Durham: Duke University Press, 2016. p. 12-27.

CALDEIRA, T. P. do R. Cidade de muros: crime, segregação e cidadania em São Paulo. São Paulo: Editora 34: Edusp, 2000. 
CALDEIRA, T. P. do R. Qual a novidade dos rolezinhos? Espaço público, desigualdade e mudança em São Paulo. Novos Estudos CEBRAP, n. 98, p. 13-20, 2014.

CARDOSO DE OLIVEIRA, L. R. Cidadania, direitos e diversidade. Anuário Antropológico, v. 40, n. 1, p. 43-53, 2015.

CARVALHO, M.; CARRARA, S. Em direção a um futuro trans? Contribuição para a história do movimento de travestis e transexuais no Brasil. Sexualidad, Salud y Sociedad: Revista Latinoamericana, v. 14, n. 2, p. 319-351, 2013.

CARVALHO, M.; CARRARA, S. Ciberativismo trans: considerações sobre uma nova geração militante. Contemporanea, v. 13, n. 2, p. 382-400, 2015.

CENTROS e margens: direito à cidade e corpos dissidentes. MAM, 1 jul. 2018. Disponível em: https://mam.org.br/evento/92731/. Acesso em: 18 jul. 2018.

CICLA das 5: Revolta da Lâmpada + FESPSP. Facebook, 5 out. 2015. Disponível em: https://www.facebook.com/events/1501581700154336/. Acesso em: 18 jan. 2018.

COLLING, L. Que os outros sejam o normal: tensões entre movimento LGBT e ativismos queer. Salvador: EdUFBA, 2015.

CONDEPE pede abertura de processo contra deputado do PSL que atacou Erica Malunguinho. Fórum, 26 abr. 2019. Disponível em: https://www.revistaforum.com. br/condepe-pede-abertura-de-processo-contra-deputado-do-psl-que-atacou-erica-malunguinho/. Acesso em: 27 abr. 2019.

CORREA, M. Do feminismo aos estudos de gênero no Brasil: um exemplo pessoal. Cadernos Pagu, n. 16, p. 13-30, 2001.

DAWSEY, J. O teatro dos "bóias-frias": repensando a antropologia da performance. Horizontes Antropológicos, Porto Alegre, ano 11, n. 24, p. 15-34, 2005.

DI GIOVANNI, J. R. Artes do impossível: ação de rua no movimento antiglobalização. São Paulo: Annablume, 2012.

DI GIOVANNI, J. R. Artes de abrir espaço. Apontamentos para a análise de práticas em trânsito entre arte e ativismo. Cadernos de Arte e Antropologia, v. 4, n. 2, p. 13-27, 2015.

DIREITO à cidade: de olho na LGBTfobia. Facebook, 17 maio 2019. Disponível em: https://www.facebook.com/events/281525112735551/. Acesso em: 17 maio 2019.

FACCHINI, R. Sopa de letrinhas?: movimento homossexual e produção de identidades coletivas nos anos 90. Rio de Janeiro: Garamond, 2005.

FACCHINI, R. Múltiplas identidades, diferentes enquadramentos e visibilidades: um olhar para os 40 anos do movimento LGBTI. In: GREEN, J. et al. (org.). História do Movimento LGBT no Brasil. São Paulo: Alameda, 2018. p. 311-330. 
FACCHINI, R.; SÍVORI, H. Dossiê Conservadorismo, direitos, moralidades e violência. Cadernos Pagu, n. 50, 2017.

FERREIRA, L. B. [ALERTA TEXTÃO] Estratégias de engajamento do movimento LGBT de São Paulo em espaços de interação on-line e off-line (2015-2016). 2017. Dissertação (Mestrado em Antropologia Social) - Faculdade de Filosofia, Letras e Ciências Humanas, Universidade de São Paulo, São Paulo, 2017.

FOSTER, H. The artist as ethnographer?. In: MARCUS, G.; MYERS, F. (ed.). The traffic in culture: refiguring art and anthropology. Berkeley: University of California Press, 1995. p. 302-309.

FOUCAULT, M. Em defesa da sociedade: curso no Collège de France (1975-1976). São Paulo: Martins Fontes, 2005.

FRANÇA, I. L. Consumindo lugares, consumindo nos lugares: homossexualidade, consumo e subjetividades na cidade de São Paulo. Rio de Janeiro: EDUERJ, 2012.

FRÚGOLI JR., H. Ativismos urbanos em São Paulo. Cadernos CRH, v. 31, n. 82, p. 75-86, 2018.

GEERTZ, C. A interpretação das culturas. Rio de Janeiro: LTC, 1989.

GOMES, C. de C. Corpo, emoção e identidade no campo feminista contemporâneo brasileiro: a Marcha das Vadias do Rio de Janeiro. 2018. Tese (Doutorado em Sociologia e Antropologia) - Instituto de Filosofia e Ciências Sociais, Universidade Federal do Rio de Janeiro, Rio de Janeiro, 2018.

GRUNVALD, V. Butler, a abjeção e seu esgotamento. In: DÍAZ-BENÍTEZ, M. E.; FÍGARI, C. (org.). Corpos, desejos, prazeres e práticas sexuais dissidentes. Rio de Janeiro: Garamond, 2009a. p. 31-70.

GRUNVALD, V. Teseu e o touro: algumas sugestões feministas para uma crítica da razão. 2009. Dissertação (Mestrado em Antropologia Social) - Museu Nacional, Universidade Federal do Rio de Janeiro, Rio de Janeiro, 2009b.

GRUNVALD, V. Algumas reflexões pessoais sobre a descolonização da queer. In: CIDADE queer: uma leitora. São Paulo: Edições Aurora, 2017. p. 22-33.

HARAWAY, D. Saberes localizados: a questão da ciência para o feminismo e o privilégio da perspectiva parcial. Cadernos Pagu, n. 5, p. 7-41, 1995.

HEILBORN, M. L.; SORJ, B. Estudos de gênero no Brasil. In: O QUE LER na ciência social brasileira (1970-1995): sociologia (volume II). São Paulo: Editora Sumaré: Anpocs, 1999. p. 183-221.

HOLSTON, J. Insurgent citizenship: disjunctions of democracy and modernity in Brazil. Princeton: Princeton University Press, 2008. 
JUNQUEIRA, R. "Ideologia de gênero": a gênese de uma categoria política reacionária - ou: a promoção dos direitos humanos se tornou uma "ameaça à família natural"?. In: RIBEIRO, P. R. C., MAGALHÃES, J. C. (org.). Debates contemporâneos sobre educação para a sexualidade. Rio Grande: Ed. da FURG, 2017. p. 25-52.

KUHAR, R.; PATERNOTTE, D. Anti-gender campaigns in Europe: mobilizing against equality. London: Rowman \& Littlefield International, 2017.

LANDER, E. (org.). La colonialidad del saber: eurocentrismo y ciencias sociales. Buenos Aires: CLACSO, 2000.

LETÍCIA Sabatella exagera na dose e deita no chão de Brasília. BOL, 5 nov. 2014. Disponível em: https://www.bol.uol.com.br/fotos/2014/11/05/leticia-sabatella-exagera-na-dose-e-deita-no-chao-de-brasilia.htm?mode=list\&foto=3. Acesso em: 18 jan. 2018.

LIMA, S. As bi, as gay, as trava, as sapatão tão tudo organizada pra fazer revolução!: uma análise socioantropológica do Encontro Nacional Universitário de Diversidade Sexual (ENUDS). 2016. Dissertação (Mestrado em Saúde Coletiva) - Instituto de Medicina Social, Universidade Estadual do Rio de Janeiro, Rio de Janeiro, 2016.

MACHADO, L. Z. O aborto como direito e o aborto como crime: o retrocesso neoconservador. Cadernos Pagu, n. 50, e17504, 2017.

MARCUS, G.; MYERS, F. The traffic in art and culture: an introduction. In: MARCUS, G.; MYERS, F. (ed.). The traffic in culture: refiguring art and anthropology. Berkeley: University of California Press, 1995. p. 1-51.

MBEMBE, A. Necropolítica. Artes e Ensaios, n. 32, p. 122-151, 2016.

MESQUITA, A. Insurgências poéticas: arte ativista e ação coletiva. São Paulo: Annablume: Fapesp, 2011.

MINI-REVOLTA no MASP para a oficina Artivismo da Fechação. Facebook, 28 maio 2017. Disponível em: https://www.facebook.com/events/145116666032552/. Acesso em: 18 jan. 2018.

MOMBAÇA, J. Desmontando a caravela queer. In: CATÁLOGO forumdoc.bh.2016. Belo Horizonte: Filmes de Quintal, 2016. p. 195-202.

MOUFFE, C.; LACLAU, E. Hegemony and socialist strategy. London: Verso, 1986.

MÜLLER, T. M. P.; CARDOSO, L. Branquitude: estudos sobre a identidade branca no Brasil. Curitiba: Appris, 2017.

PASSAÇO de cadáver do Eduardo Cunha. Facebook, 1 mar. 2015. Disponível em: https://www.facebook.com/events/573346616135374/. Acesso em: 6 jan. 2018. 
PELÚCIO, L. Subalterno quem, cara-pálida? Apontamentos às margens sobre pós-colonialismos, feminismos e estudos queer. Contemporânea, v. 2, n. 2, p. 395-418, 2012. PELÚCIO, L. O cu (de) Preciado? Estratégias cucarachas para não higienizar o queer no Brasil. Iberic@l: Revue d'études ibériques et ibéro-américaines, n. 9, p. 123-136, 2016.

PEREIRA, P. P. G. Queer nos trópicos. Contemporânea, v. 2, n. 2, p. 371-394, 2012.

PEREIRA, P. P. G. Queer decolonial: quando as teorias viajam. Contemporânea, v. 5, n. 2, p. 411-437, 2015.

PISCITELLI, A. Interseccionali dades, categorias de articulação e experiências de migrantes brasileiras. Sociedade e Cultura, v. 11, n. 2, p. 263-274, jul./dez. 2008.

PRECIADO, [P.] B. Manifiesto contra-sexual. Madrid: Opera Prima, 2002.

PUAR, J. Terrorist assemblages: homonationalism in queer times. Durham: Duke University Press, 2007.

QUIJANO, A. Coloniality and modernity/rationality. In: MIGNOLO, W.; ESCOBAR, A. (ed.). Globalization and the decolonial option. New York: Routledge, 2010. p. 22-32.

A REVOLTA da Lâmpada. Facebook, 16 nov. 2014. Disponível em: https://www.facebook.com/events/313202068879711/. Acesso em: 6 jan. 2018.

A REVOLTA DA LÂMPADA. Konvokatórya - A Revolta da Lâmpada 2017!!!!!! Facebook, 18 set. 2017. Disponível em: https://www.facebook.com/arevoltadalampada/ photos/a.\%201469985736555325/1921551304732097/. Acesso em: 18 jan. 2018.

A REVOlTA DA LÂMPADA. Fervo também é lucro. Facebook, 7 fev. 2018. Disponível em: https://www.facebook.com/arevoltadalampada/posts/ fervo-tamb\%C3\%A9 m-\%C3\%A9-lucrool\%C3\%Al-amigues-de-margem-de-desvio-de-dissid\%C3\%AAncia-a-essa-altura/1982060632014497/. Acesso em: 7 maio 2018.

RIBEIRO, R. J. A palavra democrática: ou da utopia da necessidade à utopia poética. Revista USP, n. 37, p. 102-107, 1998.

RODOVALHO, A. M. O cis pelo trans. Revista Estudos Feministas, v. 25, n. 1, p. 365-373, 2017.

RUBIN, G. Thinking sex. In: ABELOVE, H. et al. The lesbian and gay studies reader. London: Routledge, 1992. p. 143-178.

SABSAY, L. Dilemas queer contemporáneos: ciudadanías sexuales, orientalismo y subjetividades liberales. Un diálogo con Leticia Sabsay. Íconos: Revista de Ciencias Sociales, n. 47, p. 103-118, 2013. 
SABSAY, L. The political imaginary of sexual freedom. London: Palgrave, 2016.

SANSI, R. Art, anthropology and the gift. London: Bloomsbury, 2015.

TELLES, V. da S. Direitos sociais: afinal do que se trata?. In: DIREITOS sociais: afinal do que se trata?. Belo Horizonte: Ed. UFMG, 1999. p. 169-194.

TURNER, V. O processo ritual: estrutura e anti-estrutura. Petrópolis: Vozes, 1974.

VANCE, C. Pleasure and danger: toward a politics of sexuality. In: VANCE, C. (ed.). Pleasure and danger: exploring female sexuality. Boston: Routledge \& Kegan Paul, 1984. p. 1-27.

VERGUEIRO, V. Por inflexões decoloniais de corpos e identidades de gênero inconformes: uma análise autoetnográfica da cisgeneridade como normatividade. 2015. Dissertação (Mestrado Multidisciplinar em Cultura e Sociedade) - Instituto de Humanidades, Artes e Ciências Professor Milton Santos, Universidade Federal da Bahia, Salvador, 2015.

WEEKS, J. Coming out: homosexual politics in Britain, from the Nineteenth Century to the present. London: Quartet, 1977.

Recebido: 01/10/2018 Aceito: 15/04/2019 | Received:10/01/2018 Accepted: 4/15/2019 